\title{
Improving Police-Public Conflict Resolution to Improve Sustainability Decision Strategy
}

\author{
Pp. Rutherford Johnson \\ University of Minnesota Crookston, Crookston, Minnesota, USA \\ Email: ruddbaron@aol.com
}

How to cite this paper: Johnson, P. R. (2021). Improving Police-Public Conflict Resolution to Improve Sustainability Decision Strategy. Journal of Human Resource and Sustainability Studies, 9, 570-595. https://doi.org/10.4236/jhrss.2021.94036

Received: October 8, 2021

Accepted: December 11, 2021

Published: December 14, 2021

Copyright (อ 2021 by author(s) and Scientific Research Publishing Inc. This work is licensed under the Creative Commons Attribution International License (CC BY 4.0).

http://creativecommons.org/licenses/by/4.0/ (c) (i) Open Access

\begin{abstract}
Negative police-public interactions in the United States and around the world raise legitimate concerns about human rights, public safety, and negative externalities that directly impact on UN Sustainable Development Goals 1 (No Poverty), 10 (Reduced Inequalities), and 16 (Peace, Justice, and Stronger Institutions). These interactions can be in the form of unnecessary or avoidable arrests, unpleasant vocal exchanges, physical violence, and even lethal force. Such events have happened in the United States and in other countries to a level that has caused concern both in government and in the public. These negative interactions can both exacerbate and stem from inequalities and act against both true justice and local peace, as well as easily weaken valuable institutions. In order to gain insight for the purpose of improving these aspects of social sustainability, such negative police-public interactions can be conceptualised by mechanisms of strategic interaction and subconscious games. That conceptual framework can provide underlying justification for a pathway to improvement. This study applies a multipoint gravitational model as a model of influence, and considers the presence of subconscious games in the style of Eric Berne and their impact on strategic interaction. The study then subdivides the police, government, and public into several logical categories regarding attitudes and opinions and associated decision strategy regarding negative police-public interaction, and models them according to Choice Waves within the framework of the Theory of Economic Parallel Rationality. That is then used to propose a mechanism for reducing and potentially eliminating negative police-public interactions and provide mathematical, statistical, and logical justification for improvement pathways. The current apparent misalignment of incentives identified in the study will continue to provide a significant challenge to overcome. The result of not doing so, however, is a continued cost to peace, true justice, and strength of institutions. This study's ultimate purpose is to apply strategic decision analysis to help reduce violence and other forms of negative results during interactions be-
\end{abstract}


tween the police and the public.

\section{Keywords}

Police Violence, Decision Strategy, Strategic Analysis, Parallel Rationality, Choice Wave

\section{Introduction}

Negative police-public interactions in the United States and around the world naturally raise concerns about human rights, public safety, and negative externalities. This has direct impact on UN Sustainable Development Goals 1 (No Poverty), 10 (Reduced Inequalities), and 16 (Peace, Justice, and Stronger Institutions). These interactions can be in the form of unnecessary or avoidable arrests, unpleasant vocal exchanges, physical violence, and even lethal force. They can take place during encounters in public such as traffic stops, or they can take place once an individual is in custody. Such events have happened in the United States and in other countries to a level that has caused dramatic and significant concern both in government and in the public.

Although these interactions can involve members of the public from any racial or ethnic background, statistics demonstrate that the majority are from two specific racial/ethnic communities, viz., African American and Hispanic (Peoples, 2020). While overall it appears that the majority of police violence is against African-Americans, in some areas, such as California, it is predominantly Hispanics (Koran, 2020).

These negative interactions can both exacerbate and stem from inequalities and act against both true justice and local peace, as well as easily weaken valuable institutions (Trinkner, Kerrison, \& Goff, 2019). Since these negative encounters often involve ethnic minorities, systemic distrust of the police can result, which can perpetuate through generations as youth witness incidents involving adults from the community and may even have their own direct experiences (Outland, 2021). Additionally, particularly where negative interactions lead to unjust outcomes, poverty can be increased due to the correlation between criminal record and poverty (Halushka, 2020).

In order to gain insight for the purpose of improving these aspects of social sustainability, such negative police-public interactions can be conceptualised by mechanisms of strategic interaction and subconscious games. That conceptual framework can provide underlying justification for a pathway to improvement.

Actors in a setting of strategic interaction exert various forms of influence over each other, whether consciously or subconsciously. In ongoing games, the interaction between one set of actors in one round of the game may influence an entirely different set of actors in a different round of the game. For example, the interaction between $\mathrm{A}$ and $\mathrm{B}$, a member of the police and the public respectively, may exert influence on $\mathrm{C}$ and $\mathrm{D}$, an entirely different member of the police and 
public in a completely different interaction. Furthermore, this type of influence may be experienced by those who do not know each other at all and may be completely geographically dispersed. Subconscious games may result due to this influence, and the results of subconscious games may in turn contribute to influence factors.

When considering the case of negative police-public interaction, this study applies a multipoint gravitational model as a model of influence, and considers the presence of subconscious games in the style of Eric Berne and their impact on strategic interaction. The study then subdivides the police, government, and public into several logical categories regarding attitudes and opinions and associated decision strategy regarding negative police-public interaction, and models them according to Choice Waves within the framework of the Theory of Economic Parallel Rationality. That is then used to propose a mechanism for reducing and potentially eliminating negative police-public interactions and provide mathematical, statistical, and logical justification for that proposal. This study's ultimate purpose is to apply strategic decision analysis to help reduce violence and other forms of negative results during interactions between the police and the public. To do so, the case of police violence in the United State is used as an example of parallel rationality analysis of a conflict situation with the social sustainability implication of impact to social justice and human rights. That case also will be used demonstrate the influence of subconscious transactional analysis games that can yield a sub optimal outcome to various portions of the triple bottom line. The analysis demonstrates not only a theoretical model, but also points to likely areas and causes of effects, as well as mechanisms for solutions and implications of such solutions.

In considering the situation of excessive and inappropriate violence resulting from police-public interaction and racial skewness in such violence, which will be used as a case study to demonstrate general applicability of the underlying analytical approach and conceptual theory, this study seeks to answer the question: Is society focused on the wrong mechanism in police-public interaction policy? That is, are society and government currently pursuing a solution in the most effective and efficient manner, or is there a better way? In order to answer that question, this study utilises a framework of parallel rationality in the mathematics of the choice wave in order to model misalignment of incentives, strategic interaction, and subconscious games with the goal of identifying effective policy approaches that help to reduce or eliminate racial skewness in excessive and inappropriate police-public violence and to reduce or eliminate excessive and inappropriate police-public violence overall.

\section{Underlying Social Sustainability Question of Police-Public Interaction}

Sustainability is certainly a growing field that is touching more and more aspects of life around the world. It is, for example, becoming more of an integral part of business. Yet, with that growing diversity of application comes a continuing and 
even growing diversity of opinion on the legitimacy and role of sustainability, both in general and in specific applications. This case within the present study is particularly focused on the social sustainability issue of police-public interaction, which relates to United Nations Sustainable Development Goals 10 (Reduced Inequalities) and 16 (Peace and Justice; Strong Institutions) ("About the Sustainable," n.d.). Additionally, police brutality, as well as police-public problems in general, has the potential to impact supply chains (Mock, 2020; Merelli, 2020; Genovese, 2020). In addition to the social justice component towards both the police and the public, such supply chain shocks can yield suboptimal outcomes on the market side. That can lead logically to negative effects to all three components of the triple bottom line. First are the obvious financial impacts to both in-product companies and companies within the supply chain, along with their accompanying multiplier effect. Additionally, the social component of the triple bottom line can be negatively impacted in a variety of ways, including the potential for a reduction of jobs. For example, a company could decide not to locate in a specific city due to police-public conflict (Genovese, 2020). The environmental bottom line could definitely also be impacted. For example, if a company decided not to purchase from a specific supplier or that supplier were no longer able to provide the inputs to the company due to police-public conflict, the company may end up purchasing its inputs from other suppliers that use less sustainable methods.

The theory of parallel rationality and its accompanying mathematical principle of the Choice Wave with a multipoint gravitational model component will be used as the basis to propose a subdivision of the United States population into different types (affinity groups) according to viewpoints on the issue of excessive and inappropriate violence in police-public interaction. This then can provide insight into the interaction between those types, pointing to potential pathways to solutions. The ultimate purpose is to improve strategic decision making in police-public situations given that actors must make joint decisions or must make decisions that impact each other in an overall situation of significant divergent viewpoints and/or misaligned incentives. Such interactions include direct interaction between police and the public and also government policy, which impacts both the police and the public. The government is influenced by both the police and the public. The public is similarly influenced by the government and also by the police including their historic interaction with the police.

\section{Methodological Assumptions}

The underlying assumptions in this study's methodology are:

1) There exists a condition of divergent viewpoints regarding excessive and inappropriate police-public violence such that the relevant decision strategy of various types of individuals (affinity groups) in the population constitute parallel planes of rationality that do not necessarily interact with each other.

2) Based on the parallel planes of rationality, there exists a condition of misa- 
lignment of incentives between the types of individuals in those separate planes on the issue of police-public violence.

3) Decision strategy by all actors is probabilistic in nature.

4) There exists the potential for transactional analysis subconscious games in police-public interactions. Such games may account for problematic encounters.

\section{Research Methods}

Since individuals, countries, and regions do not exist in a vacuum, it is entirely reasonable to expect that they influence each other and are influenced by each other. That can be modeled by the inclusion of components of a multipoint gravitational model, which is derived from the general gravitational models in physics (Johnson, 2017b). The unique aspect of the multipoint gravitational model (which comes from the field of economics, but has additional applications to other fields) is that it does not simply focus on a single "gravitational centre" that influences other smaller actors, but treats each actor as capable of both being influenced by and influencing all other actors (though the individual influence may be so small that it might be negligible). It also considers that the influence is based on "effective distance," rather than geographical distance (Johnson, 2017a). For example, an individual in Cambridge, Massachusetts, might be more influenced, due to the internet, by an individual or a country on the other side of the world than someone on the same street in Cambridge. Such effects of influence of various types of individuals regarding sustainability belief and/or the influence between different countries on each other and on industry can be included in models to gain better understanding of situations for the purpose of better informing both government and corporate sustainability policy, helping to ensure that it is not only environmentally and financially sound, but also socially just.

In addition, economic parallel rationality and its associated mathematical Choice Wave are used to model the strategic interaction between the various actors and, importantly, stakeholders in police-public interaction. This is used to look for areas of statistically significantly different decision strategies between groups regarding police-public interaction. The identification of misalignment of incentives is used to identify potential areas in which aligning mechanisms, known as "bridges," may be applied.

Additionally, it must be noted that, when considering actors and stakeholders with different decision strategies interacting with each other, it is often tempting to segregate people into groups according to by ready-made boundaries. Those boundaries can be geographical borders, political party affiliation, race or ethnicity, economic group, and so forth. However, such boundaries do not necessarily reflect the most accurate distribution of belief (Johnson, 2015; 2016). For example, some individuals in France may think similarly to some within the United States, and others in France may think similarly to some found in Germany. In Johnson (2015), charitable giving in the US was re-analysed in a parallel 
rationality framework and, using a geospatial form of Choice Waves, it was demonstrated that the arbitrary regions selected in the original study were not necessarily the best way to describe beliefs and actions in the US regarding charitable giving. That is, there were some regions that, despite being geographically distinct, actually behaved similarly to one or more regions and distinct from others. One region was found to be, in a Choice Wave model framework, a linear combination of two other Choice Waves of other regions, suggesting that its regional boundary was inappropriate and thus should have been broken into at least two regions, grouped with others that behaved similarly (Johnson, 2015).

Then, transactional analysis is incorporated as a means of explaining any police-public interaction, positive or negative. Transactional analysis is built on the concept of subconscious interaction, which may be useful in the interpretation of outcomes and their root causes, given the ethnic disparity in a negative police-public interaction occurrence. One particular subconscious game common to transactional analysis is used as a means of explaining a least some negative police-public interactions.

\subsection{Parallel Rationality and the Choice Wave}

In order to build a robust model of strategic interaction between the police and public, as well as the impact and influence of the various stakeholders, a framework of parallel rationality is used. Consider the existence of multiple "affinity groups" (referred to in this framework as "types") of individuals in a given population, each maximising utility based on their own decision strategies, and, on average, those types are grouped such that they are statistically different from each and every other type. Each such type may be represented by a Choice Wave, which is derived from quantum mechanics and is by definition mathematically orthogonal to each and every other Choice Wave (Johnson, 2007; Johnson, 2012).

The Theory of Economic Parallel Rationality and the Choice Wave built on earlier work in behavioural economics, particularly that of recent Nobel laureates Richard Thaler and David Kahneman, as well as Matthew Rabin and Amos Tversky. They, among others, noted that there is a psychological aspect to economics (Kahneman \& Tversky, 1979; Rabin, 1998; Russell \& Thaler, 1985). The concept of "quasi-rationality" was developed in which individuals may deviate from classical rationality, causing outcomes that differ from those predicted by standard economic models, suggesting that people are indeed different (Russell \& Thaler, 1985). Parallel Rationality takes the concept further, suggesting that there are indeed distinct types of individuals who think similarly to the average of their type, but distinct from that of each and every other type (Johnson, 2012; Johnson \& Walker, 2018). And, each such type is not defined as "rational" or "quasi-rational," but rather each as inherently rational according to their own decision strategy (Johnson, 2012; Johnson \& Walker, 2018). Rather than pigeonholing people, this approach seeks to understand people better, an essential element to working towards improving social sustainability in the spe- 
cific realm of police-public interaction. Seeing social sustainability in this way can positively impact decisions made by government, police, and the public regarding police-public interaction.

\subsection{Parallel "Worlds"}

Each type constitutes a non-interacting parallel "world," each with its own distinct rationality. Individuals in each parallel "world" maximise utility according to their own rationality, as contained within their decision strategy, and distinctly from those in other "worlds" (Johnson \& Walker, 2018). The classical "straw man" still exists, but there is an infinite number of different versions of him in an infinite number of parallel "economic worlds" (Johnson \& Walker, 2018).

Consider the specific question of social sustainability beliefs regarding police-public violence. Two or more parallel rationalities (represented by mathematically orthogonal Choice Waves) may represent various stakeholders in a particular scenario. Normalising for all other issues held constant, two or more types of individuals may exist specifically regarding their police-public violence beliefs, which necessarily impacts their decision strategies. If the decision strategy of each parallel state of rationality chooses an outcome significantly different from the other stakeholders, then there is a misalignment of incentives, and an inefficient allocation of resources and sub-optimal outcomes may potentially result. A "bridge," in the form of an institution or mechanism, is necessary to span the two economic worlds and align their incentives to create a more efficient allocation of resources and a more optimal outcome (Johnson \& Walker, 2018). Bridges may be of varying magnitudes, from a weak bridge, analogous to a simple rope bridge, to a strong one, analogous to a major rail or automobile bridge. The magnitude of the bridge can depend on a variety of factors and also influences the degree to which incentives may be aligned across worlds.

\subsection{Choice Waves}

The mathematical probability function defining all possible utility maximising choices of an individual is known in the framework of economic parallel rationality as a Choice Wave. The Choice Wave assumes utility that is continuous, probabilistic, varies in a non-random manner over time, always leads to temporal utility maximisation, and permits the existence of one or more individuals (or types) who choose according to unique decision strategies (Johnson, 2012).

The Choice Wave has multiple benefits. First, it conceptually permits individuals to make different choices at each decision point and still be utility-maximising and rational (Johnson, 2012). Before the individual makes a choice, each utility-maximising possible choice has a certain probability of being the one chosen (Johnson, 2012). At the point of decision, the choice is made, revealing individual preference at that exact moment. As the various factors that comprise the decision strategy are considered within the mind, the outcome is 
probabilistic until the choice has been revealed at the decision point (Johnson, 2012). At the decision point, the probability that the consumer will choose the level of expenditure becomes 1 . Before the decision, all utility-maximising choices are possible, each with a certain probability.

Given the probabilistic nature of choice as modeled by the Choice Wave, indifference curves pertaining to individual utility are necessarily also probabilistic. Along the constraint function, indifference curves are considered to "float" until the moment of decision, at which point the classical maximisation result occurs (Johnson, 2007).

\subsection{Creating Bridges across Groups with Statistically Independent Decision Strategies}

As previously stated, a bridge is a mechanism, usually outside the direct actors in a strategic interaction, that aligns incentives. When two or more parallel worlds exist in a particular transaction or interaction system, a bridge is needed in order to align incentives if the misalignment of incentives is creating a suboptimal outcome from the transaction or interaction (Johnson \& Walker, 2018). Bridges may be classified as weak or strong. On occasion bridges can occur naturally, though that is quite rare (Johnson \& Walker, 2018). Most bridges are classified as artificial in nature, meaning they are external (Johnson \& Walker, 2018).

Assume that two random types of actors denoted as $\mathrm{W}$ and $\mathrm{K}$ are represented by two separate Choice Waves, which are orthogonal. They then may be said to exist in parallel planes of rationality in an $n$-dimensional Hilbert space. That is, their decision strategies are intrinsically different and mutually exclusive, i.e., non-interacting. Therefore, it is possible that such actors, if they find themselves in a transaction or interaction, would choose different levels of the sustainability good, $s$, which in the case of this study is the social sustainability good known as "good policing," i.e., the absence of excessive and inappropriate violence in police-public interaction. That potentially becomes problematic, given the likelihood of overlapping nature of reality between the two actors coupled with the non-interacting decision strategies. That is, the police, public, and government, even if their decision strategies happen to be orthogonal, implying that they exist in parallel worlds of rationality, nevertheless still interact with each other in the physical and policy spheres. Without a bridge, the expectation value of $s$ is that given in Equation (1) (Johnson \& Walker, 2018), where $x$ refers to all other relevant choices of concurrent decisions, and $B$ refers to the presence of a bridge or not. Orthogonality suggests that, in a two actor example, $\left\langle s_{W}\right\rangle \neq\left\langle s_{K}\right\rangle$.

$$
\left.\left\langle s_{i}\right\rangle\right|_{x, B=0}=z_{i}\left(\psi_{i}\left(s_{i}\right)_{t}\right)
$$

If some sort of bridge exists, that is, there exists in the system some sort of mechanism that might allow for an alignment of incentives between the two actors during a transaction or interaction, then $B>0$. A so-called "perfect" bridge could be represented by Equations (2) and (3) below (Johnson \& Walker, 2018). 


$$
\begin{gathered}
z_{W}\left(\psi_{W}\left(s_{W}\right)_{t}\right)=z_{K}\left(\psi_{K}\left(s_{K}\right)_{t}\right) \\
\left\langle s_{W}\right\rangle_{x, B>0}=\left.\left\langle s_{K}\right\rangle\right|_{x, B>0}
\end{gathered}
$$

In the case of the rare occurrence known as a naturally occurring bridge, $B=0$. That implies that there is some sort of weak interaction at some point that takes place between the two parallel worlds during a transaction or interaction, even though $\left\langle s_{W}\right\rangle \neq\left\langle s_{K}\right\rangle$. That can be thought of as a "lucky occurrence." In most cases, particularly those of significant viewpoint polarisation between several actors, it is not likely to be the result, but it can nevertheless happen. Following Johnson and Walker (2018), the probability of that outcome over some range is given by Equation (4).

$$
P_{\text {Bridge }}=\sum_{i, j}\left\{\int_{a_{i}}^{a_{j}} \psi_{W}\left(s_{W}\right) \mathrm{d} s_{W}+\int_{a_{i}}^{a_{j}} \psi_{K}\left(s_{K}\right) \mathrm{d} s_{K}\right\}
$$

\subsection{Distinct Worlds in Police-Public Interaction}

In the specific case considering excessive and inappropriate violence in police-public interaction, it must be remembered that such violence can occur in both directions (Rodenberg, 2020; Berman \& Wax-Thibodeaux, 2020). Given the current situation in the United States, as well as likely ease of rapid policy implementation regarding police relative to policies pertaining to the public, at least theoretically, this analysis will focus specifically on violence committed by police against the public. The principles, however, remain the same in analysing the inverse situation.

The broad categories of relevant actors and stakeholders are reasonably considered to be, then, the police, the public, and the government. A question arises as to where the media is included. Often considering itself the "fourth estate," it is understandably difficult to fit. In this study, the media will be considered to be part of the public and also potentially part of bridging mechanisms.

Within each of the broad categories, then, it is reasonable to consider that there exist several types of individuals that have different viewpoints on the issue of police brutality that could be modeled by orthogonal Choice Waves. Within the police category, reasonable divisions based on viewpoints could be those police who actually believe in and/or take part in police brutality, those police who are good officers and actively oppose police brutality, and police who are otherwise good officers, but are indifferent to the brutality carried out by other police. Within the government category, reasonable divisions are those government officials (such as legislators) who enable police brutality and approve of it, those officials who disapprove of brutality and work against it, and those who disapprove of brutality and hamper the police overall. Within the public category, reasonable divisions are those citizens who actively support police brutality and approve of it, those citizens who support to the police, but oppose police brutality, and those citizens who oppose the police in general. Those subdivisions point to three general categories of affinity groups, which are denoted as $i, j$, and $k$ in Table 1 . 
Table 1. Categories of individuals grouped according to parallel world.

\begin{tabular}{ccc}
\hline Police & Government & Public \\
\hline i. Negative Actors & i. Enable Negative & i. Support Negative \\
j. Positive Actors, Oppose Negative & j. Support Police, Disable Negative & j. Support Police, Oppose Negative \\
k. Indifferent & k. Hamper Police & k. Oppose Police \\
\hline
\end{tabular}

In Table 1, the percentage of each type that exists in a particular location reasonably would be considered to be a major contributing factor to any given situation. For example, if there is a large percentage of affinity group $i$, then it stands to reason that there will be more police brutality, general public support of it, and lack of government policy to stop it. However, the specific composition of society in a given location also may point to solutions.

\subsection{Choice Wave Representation}

The Choice Waves for the three broad categories in Table 1 are provided below, Following Johnson (2012), Johnson (2015), and Johnson (2017), in Equations (5)-(7). For each broad Choice Wave, there are Choice Waves subsets of $i, j$, and $k$ for each. It is possible that across $i, j$, and $k$ respectively, the individual choice waves are merely linear combinations of each other and therefore can be represented by one single choice wave if true. However, that is not necessarily something that can be taken as automatically given.

$$
\begin{aligned}
& \psi_{\text {Pol }}\left(s_{\text {Pol }}\right)_{t}=\left\{\begin{array}{l}
k_{\text {Pol }}^{*}\left(s_{\text {Pol }} \mid x_{\text {Pol }}\right) \text { s.t. } v\left(Y, H, \frac{F_{\text {net }}}{n_{\text {Pol }}}, B\right) \text { at the decision point; } \\
k_{t, \text { Pol }}\left(s_{\text {Pol }}, x_{\text {Pol }}\right) \text { s.t. } v\left(Y, H, \frac{F_{\text {net }}}{n_{\text {Pol }}}, B\right) \text { everywhere else. }
\end{array}\right. \\
& \psi_{\text {Gov }}\left(s_{G o v}\right)_{t}=\left\{\begin{array}{l}
k_{\text {Gov }}^{*}\left(s_{\text {Gov }} \mid x_{\text {Gov }}\right) \text { s.t. } v\left(Y, H, \frac{F_{\text {net }}}{n_{\text {Gov }}}, B\right) \text { at the decision point; } \\
k_{t, \text { Gov }}\left(s_{G \text { Gov }}, x_{\text {Gov }}\right) \text { s.t. } v\left(Y, H, \frac{F_{\text {net }}}{n_{\text {Gov }}}, B\right) \text { everywhere else. }
\end{array}\right. \\
& \psi_{\text {Pub }}\left(s_{\text {Pub }}\right)_{t}=\left\{\begin{array}{l}
k_{\text {Pub }}^{*}\left(s_{\text {Pub }} \mid x_{\text {Pub }}\right) \text { s.t. } v\left(Y, H, \frac{F_{\text {net }}}{n_{\text {Pub }}}, B\right) \text { at the decision point; } \\
k_{t, \text { Pub }}\left(s_{\text {Pub }}, X_{\text {Pub }}\right) \text { s.t. } v\left(Y, H, \frac{F_{\text {net }}}{n_{\text {Pub }}}, B\right) \text { everywhere else. }
\end{array}\right.
\end{aligned}
$$

In Equations (5)-(7) above, $k$ represents some sort of a probability function comprising all possible utility maximising choices of the social sustainability good known as "good policing," denoted as $s$, given all other relevant choices of concurrent decisions (not directly the issue of "good policing" itself), denoted as $x$, subject to some sort of a constraint (analogous to the typical income constraint in economics). Good policing necessarily has different forms depending on whether the individual is in the police, the public, or the government categories. The constraint has a monetary component, $Y$, and historical component 
denoting historical interaction between relevant actors (updated with every new interaction), $H$, a multipoint gravitational influence term, $\frac{F_{n e t}}{n}$, and a term indicating the presence and magnitude of a bridge, $B$. Since the probabilistic nature of the Choice Wave framework necessarily yields results in the form of expectation values, the expectation value of any given type, $w$, is given in Equation (8), where $z$ is some function of the Choice Wave. (The Choice Wave is the underlying "driver" of the decision strategy, and $z$ translates that into the final outcome.)

$$
\left.\left\langle s_{w}\right\rangle\right|_{x}=z_{w}\left(\psi_{w}\left(s_{w}\right)_{t}\right)
$$

\subsection{Worlds and Bridges: Example Case of Police Brutality}

In the case of police brutality, there are three broad "worlds" that could reasonably be expected to be represented by their own Choice Wave and hence the in states of parallel rationality, viz., Police, Public, and Government. Each of those three worlds, though, must interact on police matters. These three parallel worlds and their connections are depicted in Figure 1.

In Figure 1, the three worlds are connected by bridges that are also contingent. A permanent bridge between Government and Police, denoted by $B_{1}$, is termed "legislation." Similarly, the permanent bridge between Public and Government, denoted by $B_{2}$, is "voting and advocacy." Now, since government policy is at least somewhat dependent upon the public, $B_{1}$ must be contingent upon $B_{2}$ such that $\left|B_{1}\right|=f\left(\left|B_{2}\right|\right)$. Also, additional bridges could be built between Government and Police to better align incentives, and these are denoted as $B_{1 a}, B_{1 b}$, etc. above. Such bridges could create better government policy regarding policing. That implies, then, that $\left|B_{1}\right|=f\left(\left|B_{2}\right|,\left|B_{1 a}\right|,\left|B_{1 b}\right|, \cdots\right)$.

Next, there is the potential for a bridge mechanism, $B_{3}$, between Police and Public, but no such bridge necessarily exists automatically. That is, there is nothing necessarily that will automatically align Police and Public incentives, depending on the situation. Public influence of Government on policing matters is reasonably considered to be a function of its interaction with Police, and such a bridging mechanism between Police and Public will logically influence the way in which Public in turn influences Government. Therefore, $\left|B_{2}\right|=g\left(\left|B_{3}\right|\right)$, which in turn leads to $\left|B_{1}\right|=f\left(g\left|B_{3}\right|,\left|B_{1 a}\right|,\left|B_{1 b}\right|, \cdots\right)$. If problems exist in the police-public relationship, it is possible for government policy to assist. If the status quo is simply $B_{1}$ and $B_{2}$, then the bridges of $B_{1 a}, B_{1 b}$, etc. and $B_{3}$ should be the main areas of focus and are key to solving problems.

\subsection{Interaction Games}

In the absence of a naturally-occurring bridge, the establishment of an artificial (external) bridge that helps to align incentives during a transaction or interaction can be conceptualised as a strategic interaction game (Johnson, 2017). In the situation of police-public interaction, that game is not likely to be simply a 


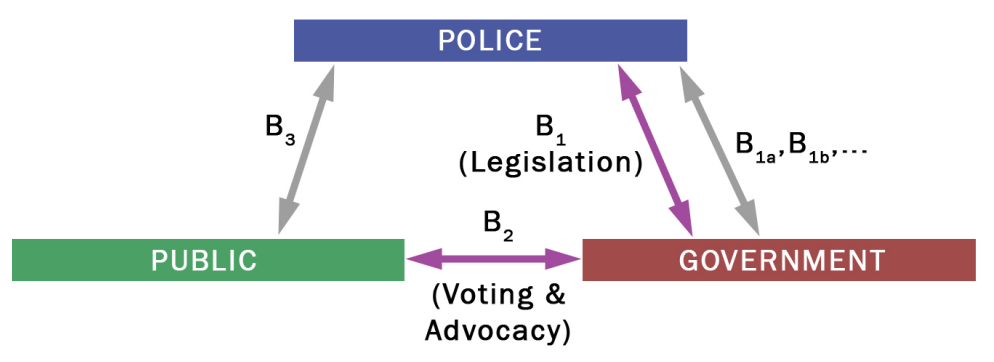

Figure 1. Parallel worlds with circular Three-Part contingent bridges.

one-shot game, but reasonably will be expected to continue for several rounds or even indefinitely, given the ongoing nature of relationship between the police and the public.

Let two actors/players $A$ and $B$ each have an initial expectation value of the social sustainability good called "good policing" given as $\left\langle{ }_{0} s_{A}\right\rangle$ and $\left.{ }_{0} s_{B}\right\rangle$ respectively. At the first decision point, each player will then make a choice driven by their underlying decision strategy (denoted by their Choice Wave) regarding the level of that sustainability good as usual. There is a probability, then, that the levels chosen by each actor will be not precisely equal, but still close enough for reasonable usefulness in achieving a reasonable outcome. For example, the two players may not agree precisely on the specific nature of police brutality, but they might nevertheless each decide upon a course of action in the first round of the game that would satisfy the strategic objectives of the other side as well. If that happens, then the game ends satisfactorily in the first round. Following Johnson (2017), the probability of that happening, then, is given as $\operatorname{Prob}\left(\left\langle{ }_{0} s_{A}\right\rangle \approx\left\langle_{0} s_{A}\right\rangle\right)$.

If the initial round does not yield expectation values that are sufficiently similar, the game must proceed to the second round. The objective of each actor in the second round is, facing Choice Waves $\psi_{i}\left(s_{i}\right)$ for the $i^{\text {th }}$ player, to obtain the outcome that eluded them in the first round, i.e., $\left\langle s_{A}\right\rangle \approx\left\langle s_{B}\right\rangle$. That probability is given by $\operatorname{Prob}\left(\left\langle s_{A}\right\rangle \approx\left\langle s_{B}\right\rangle\right)$, which is the probability that A or B can modify some aspect in their decision strategy function (as expressed by the underlying Choice Wave) or in their constraint terms to result in an outcome with expectation values sufficiently close to each other to be a satisfactory strategic outcome regarding police brutality.

The strategic interaction between the police and the public is not only ongoing, but also does not exist in a temporal vacuum. That is, each actor likely has history with the other. For example, members of the public, and especially specific racial and ethnic communities, may have memories of negative past interaction with police. Even if a specific individual has not had such an experience, the fact that others in their ethnic community have can influence their own decision strategy regarding police-public interaction. Likewise, a policeman may not have had problems with members of the public, but knowledge of other police having such problems might similarly influence their decision strategy. Additionally, players likely have been able to observe over time the interaction of 
each other with other groups and players. Such observations and experience would naturally and reasonably be expected to comprise part of the constraint of their decision strategy and also their willingness to participate in artificial bridges. Following Johnson (2017) and Johnson and Walker (2018), Equation (9) below provides the probability of a solution in the second round of the game.

$$
\operatorname{Prob}\left(\left\langle s_{A}\right\rangle \approx\left\langle s_{B}\right\rangle\right)=\operatorname{Prob}\left(\operatorname{Mod}_{A} \mid B, H_{A B}\right)+\operatorname{Prob}\left(\operatorname{Mod}_{B} \mid A, H_{A B}\right)
$$

Equation (9) states that the probability of a sufficiently satisfactory outcome in the second round is the sum of the probability that A will create a modification (whether a bridge or not) and the probability that B will act similarly. Each probability is conditional upon two points, viz., the choice made by the other player and their historical interaction, $H$.

The actions of each actor exist over time and include decisions made by the other player with third parties. For the $i^{\text {th }}$ player, that term can be expressed as $i=i_{t-1}+i_{t-2}+\cdots+i_{t-n}$, where $n$ represents the time of relevancy of the actions of the other player. Each player reasonably considers the actions of the other player only over a time period deemed by them to be relevant. Some players may have short memories, while others have long memories.

Following Johnson (2017), the probability of reaching a satisfactory outcome in the second round of the game must be the probability of moving to the second round times the probability of reaching an outcome in the second round transaction or interaction. It must be assumed that the game automatically proceeds to the second round if the first round fails, or else this probability must be modified accordingly. This is given in Equation (10), and the total probability of reaching a satisfactory outcome in either the first or the second round is given by Equation (11) (Johnson \& Walker, 2018).

$$
\begin{gathered}
P_{1}=\left[1-\operatorname{Prob}\left(\left\langle\left\langle_{0} s_{A}\right\rangle \approx\left\langle_{0} s_{A}\right\rangle\right)\right]\left[\operatorname{Prob}\left(\left\langle s_{A}\right\rangle \approx\left\langle s_{B}\right\rangle\right)\right]\right. \\
P_{\text {total }}=\operatorname{Prob}\left(\left\langle_{0} s_{A}\right\rangle \approx\left\langle{ }_{0} s_{A}\right\rangle\right)+\left[1-\operatorname{Prob}\left(\left\langle_{0} s_{A}\right\rangle \approx\left\langle{ }_{0} s_{A}\right\rangle\right)\right]\left[\operatorname{Prob}\left(\left\langle s_{A}\right\rangle \approx\left\langle s_{B}\right\rangle\right)\right] \\
=P_{0}+\left(1-P_{0}\right) P_{1}
\end{gathered}
$$

As the game progresses, each round of the game adds another level of historical interaction terms resulting from the transaction or interaction between each actor, further influencing the game (Jaffray, 1992). In a multi-round game, the total probability may be expressed as Equation (12) (Johnson, 2017).

$$
P_{\text {total }}=P_{0}+\left(1-P_{0}\right) P_{1}+\left(1-P_{0}\right)\left(1-P_{1}\right) P_{2}+\left(1-P_{0}\right)\left(1-P_{1}\right)\left(1-P_{2}\right) P_{3}+\cdots
$$

Based on the inclusion of historical interaction and the actions of each player, this can also be expressed for added clarity as Equation (13) (Johnson, 2017).

$$
\begin{aligned}
& P_{\text {total }}=P_{0}\left(A_{0}, B_{0},\left.H_{A B}\right|_{t=0}\right)+\left(1-P_{0}\left(A_{0}, B_{0},\left.H_{A B}\right|_{t=0}\right)\right) P_{1}\left(A_{1}, B_{1},\left.H_{A B}\right|_{t=1}\right) \\
& +\left(1-P_{0}\left(A_{0}, B_{0},\left.H_{A B}\right|_{t=0}\right)\right)\left(1-P_{1}\left(A_{1}, B_{1},\left.H_{A B}\right|_{t=1}\right)\right) P_{2}\left(A_{2}, B_{2},\left.H_{A B}\right|_{t=2}\right)+\cdots
\end{aligned}
$$

In Equation (13), each of the terms $A$ and $B$ contain time series information over a frame of relevancy determined by each individual actor. Each subsequent 
round adds another element. However, depending on the individual definitions of relevancy, it is possible that as the game proceeds, earlier actions by the other player may eventually "fall off the radar." For example, if a player only looks to the last decade, then each subsequent round of the game removes another year of behaviour of the other player from consideration. If, continuing the example, player A exhibited negative behaviour in the period $t$-10, with all subsequent behaviour being positive, and player B only considered up to 10 years prior to the present, then moving to the second round of the game would remove that negative behaviour from consideration, increasing the likelihood of a satisfactory outcome in the second round.

Also, recall that Equation (13) gives the probability of a modification dependent upon the history of each player with each other in the observation of the other player's interaction with third parties over time. Ultimately it is irrelevant which player modifies or if both modify. Artificial bridges can facilitate such modification, but that is not the only means possible. Since the Choice Wave defining the complete set of utility maximising choices of each actor in this scenario also contains as a constraint a mutual "gravitational" influence term, an historical term, and the potential for a bridge of some specific magnitude, any of those terms can be modified potentially to yield a satisfactory outcome. The expectation value is still obtained without modifying the absolute form of the probability function (that is, without modification of the probabilistic term itself, but only modification of terms in the constraints). Likewise, nothing requires that actor maintain the same Choice Wave on a permanent basis. Thus outcomes may change due to a change in the complete underlying decision strategy itself. That change may actually result, though, from an influence given by a change in the constraints term. For example, changes in certain constraints may make police adopt certain measures that are otherwise not in line with their decision strategy (or to be more specific, with the absolute portion of their Choice Wave), only to have that change in the terms of the constraint eventually bring about a permanent change in the underlying decision strategy, i.e., in the absolute portion of the probability wave.

\subsection{Transactional Analysis Game}

Police-public interactions may be conceptualised as transactions (Johnson, 2017; Johnson, 2017b). Both the police officer and the member of the public are players in the transaction, with each seeking to maximise utility as a result of the transaction/interaction. There exists, then, the potential for subconscious transactional analysis games that add an additional degree of complexity to such interactions and can create sub optimal outcomes (Berne, 1964).

Eric Berne, considered the founder of transactional analysis theory, explained subconscious games through a series of cleverly-named and laid-out archetypal games. One such game that is potentially relevant to police-public interactions and could explain some of such interactions that resulted in excessive and inappropriate violence is entitled Now I've Got You (abbreviated here as GOTCHA) 
(Berne, 1964). The archetypal example of the game is quoted verbatim from Berne (1964) below:

"White needed some plumbing fixtures installed, and he reviewed the costs very carefully with the plumber before giving him a go-ahead. The price was set, and it was agreed that there would be no extras. When the plumber submitted his bill, he included a few dollars extra for an unexpected valve that had to be installed about four dollars on a four-hundred-dollar job. White became infuriated, called the plumber on the phone, and demanded an explanation. The plumber would not back down. White wrote him a long letter criticizing his integrity and ethics and refused to pay the bill until the extra charge was withdrawn. The plumber finally gave in." (Berne, 1964)

In Berne's archetypal example, both White and the plumber were engaged in games of one sort of another. The plumber's actions constituted a game. $\mathrm{He}$ broke his original contractual promise and added an extra fee without first obtaining subsequent contractual modification (Berne, 1964). Whether the plumber's game was in fact subconscious or not is not necessarily clear (Berne, 1964). On the other hand, White's game, GOTCHA, was indeed a subconscious game (Berne, 1964). It causes a Parent-Adult interaction, with White exploiting his being in the right (Berne, 1964). That led a suboptimal outcome (Berne, 1964). Had the subconscious game instead been avoided, and the two parties dealt with the conflict on the Adult-Adult interaction level, an optimal outcome most likely could have been reached (Berne, 1964). Now, why is White a GOTCHA player? That could result from various causes, including pent-up frustration and various wrongs he has suffered at the hands of others, real or perceived, or his parents themselves being GOTCHA players (Berne, 1964).

In harmful transactional analysis games, including GOTCHA, the victim (in the case of the archetypal example, the plumber) must react to the game being played by the other party (Berne, 1964). That is, the presence of the game forces another component to the victim's utility maximisation problem. In the Choice Wave framework, another probabilistic component is added to the equation, leading to a utility maximisation choice that, under the presence of the game, would most likely differ from the choice in the absence of the game (Berne, 1964; Johnson, 2017; 2017b). As two players entitled "police" and "public" interact, it is impossible to know for certain a priori whether or not the other player is a player of GOTCHA (or some other harmful transactional analysis game) (Berne, 1964; Campos, 2014; Wei \& Luo, 2012; Johnson, 2017; 2017b). Similarly, it is impossible to know for certain whether the other player is a "trigger provider" that might cause a game to take place during a transaction or interaction (Johnson, 2017b). It should be noted, however, that providing a trigger does not place the fault necessarily on the trigger provider. The trigger could simply be membership in a specific ethnic or religious community. On the other hand, the trigger could be something that results from a subconscious game, such as a "chip on the shoulder" attempting to get a negative reaction from the other party (Johnson, 2017b). Historical interaction, either of the specific individual or be- 
tween members of the individual's group (such as an ethnic community) with the other player or a member of the other player's group can influence the perceived probability that the other person is either a GOTCHA player or trigger provider.

Following Johnson (2017b), in the case of GOTCHA, the possible interactions are:

1) Police plays GOTCHA. Public provides the trigger.

2) Public plays GOTCHA. Police provides the trigger.

3) Police has the potential to play GOTCHA. Public does not provide the trigger.

4) Public has the potential to play GOTCHA. Police does not provide the trigger.

5) Police and Public both have the potential to play GOTCHA. Neither provides the trigger.

6) Neither has the potential to play GOTCHA.

Regardless of player type, payoffs differ depending on the nature of specific interaction. The utility maximising strategy of Police necessarily depends on Public and vice versa, meaning that they are each two-part and contingent upon the observed and historic behaviour of the other party (Johnson 2017; 2017b). If Police is a GOTCHA player, as given in options 1,3 , and 5 in the list above, there is no dominant strategy, for game benefits only result if the trigger is provided. Indeed, there is potentially a penalty for playing the game if the trigger is not provided (Berne, 1964; Johnson, 2017b). Now, particularly given the potential violent consequences of a GOTCHA game between Police and Public, it would stand to reason that the dominant strategy of a trigger provider, whether Police or Public, would be not to provide the trigger. Nevertheless, that is not always the case, since it is possible that another subconscious game is taking place, and some triggers are inherent characteristics and impossible to avoid. A general depiction of utility is provided in the payoff matrix as given in Table 2. In the payoff matrix, if both are GOTCHA players, but neither provides the trigger, or if neither is a game player but both are trigger providers, the maximum utility is reached. Similarly, if one player is neither a GOTCHA player nor trigger provider, then, regardless of whether the other player is a GOTCHA player or trigger provider, maximum utility is likewise reached since there is no subconscious transactional analysis game. Maximum utility is given in Table 2.

In other scenarios in which one side is a GOTCHA player and the other side provides the trigger, there is a loss of utility to the player that provides the trigger and again to utility of the player that plays GOTCHA. The worst case scenario is when both are GOTCHA players and the trigger providers, in which case both Police and Public could lose utility. It is, however, indeterminate whether each player will gain or lose utility, since each player suffers a loss from providing the trigger, but a gain from playing GOTCHA.

In Table 2, it should be noted that the various options given for Police and 
Public are not specific choices to be made per se at the time of decision, but rather indicate an inherent characteristic of the player. That is, they are either a GOTCHA player or they are not; and they are either a trigger provider or they are not. Given that the game is subconscious, the actions taken during GOTCHA are considered obviously not to be a conscious choice. A trigger, on the other hand, may be subconscious, conscious, or an inherent characteristic. A trigger provider will always suffer a loss of utility unless they are also a GOTCHA player, in which case they may gain or lose. So, the payoff matrix in Table 2 represents payoffs from interactions between several types of individuals based on their inherent characteristics regarding GOTCHA and the GOTCHA trigger.

The payoffs in Table 2 also are variable, and thus it is worthwhile to consider which values may be larger or smaller. Since this study considers specifically police brutality, it would be expected that the gains in utility to Police are, due to the power differential, greater than the gains in utility to Public, and similarly the losses to Public are greater than the losses to Police (Ledgerwood, Chaiken, Gruenfeld, \& Judd, 2006; Mannix \& Neale, 1993). It is also a reasonable assumption in general that the gains in utility to Police, in the framework of violence, are less in magnitude than the loss in utility to Public. That means that GOTCHA games played by Police result in an outcome that is not Pareto efficient in that the utility winner (Police) could not compensate the utility loser (Public). That underscores the particularly troubling nature of police brutality as a highly skewed and suboptimal outcome. However, it must be noted that these are assumptions not actually based on numerical calculations of utility proxies.

Additionally, one must consider the nature of the GOTCHA game played by the public. Since the study is focused on police brutality, it is assumed that the GOTCHA game played by Public is either nonviolent or violent of a lesser magnitude than violence carried out by Police. In a broader sense of police-public interactions of violence, it must still be remembered that there is, as previously mentioned, the potential for Public to be the primary aggressor and Police be the victim. Thus such scenarios can be extrapolated by modifying the structure of the system in the police brutality model, as well as the terms of the payoff matrix and Table 2 .

Table 2. Payoff matrix for Police-Public interaction with GOTCHA game present.

\begin{tabular}{ccccc}
\hline & Public: & Public: & Public: & Public: \\
& GOTCHA & Trigger Only & Trigger + GOTCHA & Neither \\
\hline Police: & Police: $U$ & Police: $U+\alpha$ & Police: $U+\lambda$ & Police: $U$ \\
GOTCHA & Public: $U$ & Public: $U-\varepsilon$ & Public: $U-\mu$ & Public: $U$ \\
Police: & Police: $U-\beta$ & Police: $U$ & Police: $U-\nu$ & Police: $U$ \\
Trigger Only & Public: $U+\delta$ & Public: $U$ & Public: $U+\pi$ & Public: $U$ \\
Police: & Police: $U-\phi$ & Police: $U+\gamma$ & Police: $U \pm \theta$ & Police: $U$ \\
Trigger + GOTCHA & Public: $U+\chi$ & Public: $U-\kappa$ & Public: $U \pm \rho$ & Public: $U$ \\
Police: & Police: $U$ & Police: $U$ & Police: $U$ & Police: $U$ \\
Neither & Public: $U$ & Public: $U$ & Public: $U$ & Public: $U$ \\
\hline
\end{tabular}




\subsection{Choice Wave Model of GOTCHA Game}

Given the possibility of GOTCHA resulting in police-brutality, each player's faces a utility maximisation problem is expressed as a function of the Choice Wave of the player. That Choice Wave is a linear combination of: 1) the general Choice Wave related to the good of "good policing;" 2) the player's own Choice Wave regarding to GOTCHA; and 3) the Choice Wave of the other player pertaining to their likelihood of providing the trigger and their response if GOTCHA is played (Johnson, 2013). Following Johnson (2017; 2017b), Equations (14) and (15) are the Choice Waves for Police and Public.

$$
\begin{aligned}
& \text { GотСнА }_{\text {Pol }}=\left\{\begin{array}{l}
\operatorname{Prob}^{*}\left(\text { GOTCHA }_{\left.\mid \text {trigger }_{\text {Pub }}\right)}\right. \text { at the decision point; } \\
\operatorname{Prob}(\text { GOTCHA }) \text { s.t. } \text { Prob }_{\text {Pub }}(\text { trigger }) \text { otherwise. }
\end{array}\right. \\
& \text { GотCHA }_{\text {Pub }}=\left\{\begin{array}{l}
\operatorname{Prob}^{*}\left(\text { GOTCHA } \mid \text { trigger }_{\text {Pol }}\right) \text { at the decision point; } \\
\operatorname{Prob}(\text { GOTCHA }) \text { s.t. } \text { Prob }_{\text {Pol }}(\text { trigger }) \text { otherwise. }
\end{array}\right.
\end{aligned}
$$

In Equations (14) and (15), at times other than a decision point, the probability of GOTCHA taking place is necessarily and inherently subject to the probability that the trigger will be provided by Public. That is, the Choice Wave of Police is necessarily subject to the Choice Wave of Public. At the moment of interaction between Police and Public, which constitutes a decision point for both parties, Public will reveal whether or not the trigger will be provided. Therefore, the probability of Police playing GOTCHA is based on an actual outcome, i.e., whether or not the trigger has been provided, rather than a specific probability of a trigger being provided. That is, the value that is factored by Police is 0 or 1 . In the case of an inherent characteristic trigger, such as a racial or ethnic component, trigger $_{\text {Public }}$ necessarily always equals 1 . This then suggests Equations (16) and (17) below as full Choice Waves for both Police and Public.

$$
\begin{gathered}
\psi_{\text {Pol }}={ }_{\text {Pol }} \lambda_{1 s} \psi_{\text {Pol }}+{ }_{\text {Pol }} \lambda_{2 \text { GOTCHA }} \psi_{\text {Pol }}+{ }_{\text {Pol }} \lambda_{3 \text { Trigger }} \psi_{\text {Pub }} \\
\psi_{\text {Pub }}={ }_{\text {Pub }} \lambda_{1 s} \psi_{\text {Pub }}+{ }_{\text {Pub }} \lambda_{2 \text { GOTCHA }} \psi_{\text {Pub }}+{ }_{\text {Pub }} \lambda_{3 \text { Trigger }} \psi_{\text {Pol }}
\end{gathered}
$$

If the specific bundle sustainability good of "good Policing," $s$, is decided a framework in which the game of GOTCHA and triggers for that game may exist, then, following Johnson (2017) the four basic subtypes of individuals in police-public interactions can be expressed as follows in Table 3. Furthermore, each person can be expressed as either a GOTCHA player or not and also a trigger provider or not. Therefore, they may be expressed, if GOTCHA and triggers for that game may exist, Johnson (2017) as types that are combinations of subtypes, which are given in Table 4.

In police-public interactions, of GOTCHA and triggers for that game may exist, then, following Johnson (2017), the interactions between individuals of specific types that could lead to a GOTCHA game taking place are given in Table 5.

The specific probability of police of one specific type interacting with a member of the public of another specific type can be expressed as some function of 
Table 3. Sub-Types of individuals.

\begin{tabular}{cc}
\hline Sub-Type & Characteristic \\
\hline $\mathrm{N}$ & GOTCHA Player \\
$\mathrm{T}$ & Trigger Provider \\
$\mathrm{R}$ & Does not play GOTCHA $\left({ }_{N I G Y} \psi=0\right)$ \\
$\mathrm{Q}$ & Does not provide a trigger $\left({ }_{\text {Trigger }} \psi=0\right)$ \\
\hline
\end{tabular}

Table 4. Types of individuals.

\begin{tabular}{cc}
\hline Type & Characteristic \\
\hline NT & GOTCHA Player \& Trigger Provider \\
NQ & GOTCHA Player; does not provide a trigger \\
RT & Does not play GOTCHA; Trigger Provider \\
RQ & Does not play GOTCHA; Does not provide a trigger \\
\hline
\end{tabular}

Table 5. Types of individual interactions that may lead to GOTCHA.

\begin{tabular}{ccc}
\hline Police & & Public \\
\hline NT & $\leftrightarrow$ & RT \\
NT & $\leftrightarrow$ & NT \\
NQ & $\leftrightarrow$ & RT \\
NQ & $\leftrightarrow$ & NT \\
\hline
\end{tabular}

the number of police and public of each relevant type over the total number of individuals in the system. Furthermore, the likelihood of the interaction between two specific types can be further expressed as a function of the effective distance between the individuals of those two types (Johnson, 2015). That derives from the multipoint gravitational model in its economic form, in which "effective distance" is not necessarily geospatial, but refers to the potential for influence (Johnson, 2015). In the case of police-public interaction, however, it is highly likely that there will be a significant geospatial aspect to distance rather than a non-physical-distance influence. Following Johnson (2017; 2017b), this may be expressed for the police-public case as Equation (18) below.

$$
\operatorname{Prob}\left(\operatorname{Pol}_{w} \| \operatorname{Pub}_{q}\right)=\frac{f\left(N_{N T}, N_{R T}, N_{N Q}, N_{\text {total }}\right)}{g\left(r_{w q}, r_{w k}, r_{w l}, r_{w m}\right)}
$$

In Equation (18) above, the probability of interaction between police officer $W$ and member of the public $q$ is expressed as some function of the number of individuals of each type that might lead to a game of GOTCHA as a proportion of the total population, divided by some function of the relative distances between individual $w$ and $q$, as well as between $w$ and the nearest individuals of other types, denoted as individuals $k, l$, and $m$. The latter is included because there is a probability that w will interact with $k, l$, or $m$ before interacting with $q$. In gener- 
al terms, $f$ and $g$ are arbitrary functions that may be of whatever form that fits the data. For purposes of example, it could be assumed that $f$ is a linear function and $g$ is, consistent with the gravitational model, a quadratic function (Johnson, 2015; 2017b). This, then, could be expressed as Equation (19), which gives the probability of an interaction between Police of either type NT or NQ will Public of either type RT or NT. That is, it gives the probability of an interaction between Police and Public when the potential for a game exists since the types included are those that can yield an interaction in which Police plays GOTCHA.

$$
\operatorname{Prob}\left(\operatorname{Pol}_{N T: N Q} \| P u b_{R T: N T}\right)=\frac{\left(\frac{N_{P o l: N T}+N_{P o l: N Q}+N_{P u b: R T}+N_{P u b: N T}}{N_{N T}+N_{R T}+N_{N Q}+N_{R Q}}\right)}{\left(r_{P o l: N T: N Q-P u b: R T: N T}\right)^{2}+\frac{1}{\sum_{\text {for } w \neq P u b: R T: N T}\left[\left(r_{k-w}\right)^{2}\right]}}
$$

As the distance between Police of either type NT or NQ and Public of either type RT or NT reduces, the probability of an interaction between Police and Public that would lead to a game of GOTCHA increases. As the distance between Police and the Public of any type other than RT or NT increases, however, the likelihood of an interaction leading to a game of GOTCHA necessarily decreases. Given the presence of police who could play GOTCHA and members of the public who could provide the trigger, the sustainability good of "good policing" is an expectation value whose outcome depends on the interactions between the police and the public. This can be expressed, following Johnson (2017) in Equation (20), in which $p$ is a probability function, and the various $h$ terms are functions of various Choice Waves of each type of individual. Given the orthogonality of the Choice Waves, each term is necessarily in its own unique vector dimension as given. The vector Other and its corresponding Choice Wave gives the overall underlying decision framework that leads to good policing in the absence of the game, i.e., the optimal outcome. The terms $h_{1}, h_{2}, h_{3}$, and $h_{4}$ represent a deviation from a sub-optimal outcome, which is analogous to the economic concept of "quasi-rationals" (Russell \& Thaler, 1985). In the Choice Wave framework a probabilistic representation of the utility maximising choices of each of the individuals of each of those four types is permitted. That leads to a specific choice that is probabilistic and not known until the actual decision point. Thus the Choice Wave of any individual with the capacity to play GOTCHA or to provide the trigger can be represented as a linear combination of its regular/optimal decision strategy. That is, what would the individual actor do in the absence of the game, and what would they do in the presence of the game? Following Johnson (2017), Equation (20) can be expanded for the police-public case to Equation (21). Each game-related interaction results in the interaction between Police and Public acting in two separate, orthogonal vector directions, and thus the resultant function is a cross product providing a new vector direction. The interaction between a game-playing police officer and a trigger providing 
member of the public creates a joint decision strategy represented by its own Choice Wave that is the result of the vector interaction between the two individuals. This is shown in Equation (22), where $h_{5}$ represents the standard outcome in the absence of the game.

$$
\begin{aligned}
& \langle s\rangle=p\left\{h_{1}\left(\psi_{\text {Pol:NT }}\right) \widehat{P o l: N T}+h_{2}\left(\psi_{\text {Pol:NQ }}\right) \widehat{P o l: N Q}+h_{3}\left(\psi_{\text {Pub:RT }}\right) \widehat{P u b: R T}\right. \\
& \left.+h_{4}\left(\psi_{\text {Pub:NT }}\right) \widehat{\text { Pub:NT }}\right\}+h_{5}\left(\psi_{\text {other }}\right) \widehat{\text { Other }}
\end{aligned}
$$

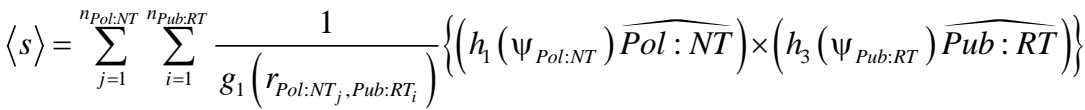

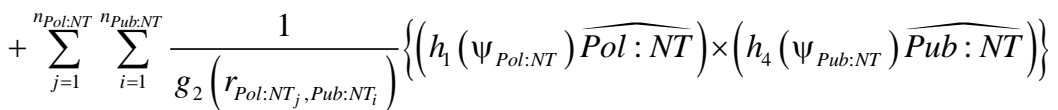

$$
\begin{aligned}
& +\sum_{j=1}^{n_{\text {Pol:NQ }}} \sum_{i=1}^{n_{\text {Pub:RT }}} \frac{1}{g_{3}\left(r_{\text {Pol: NQ }_{j}, P u b: R T_{i}}\right)}\left\{\left(h_{2}\left(\psi_{\text {Pol:NQ }}\right) \widehat{P o l: N Q}\right) \times\left(h_{3}\left(\psi_{\text {Pub:RT }}\right) \widehat{P u b: R T}\right)\right\}
\end{aligned}
$$

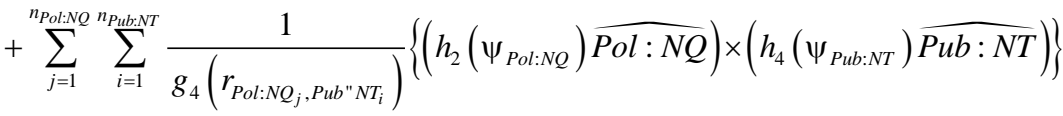

$$
\begin{aligned}
& +h_{5}\left(\psi_{\text {other }}\right) \\
& \langle s\rangle=\sum_{j=1}^{n_{\text {Pol:NT }}} \sum_{i=1}^{n_{P_{u b b}: R T}} \frac{1}{g_{1}\left(r_{{\text {Pol: } N T_{j}, P u b: R T_{i}}}\right)}\left\{\left(h_{1}\left(\psi_{\text {Pol:NT }}\right) \widehat{\text { Pol :NT }}\right)\right. \\
& \left.\times\left[\left(h_{3 a}\left(\psi_{\text {Pub:RTa }}\right) \widehat{\text { Pub:RT }}\right)+\left(h_{3 b}\left(\psi_{\text {Pub:RTb }}\right) \widehat{P u b: R T_{b}}\right)\right]\right\} \\
& +\sum_{j=1}^{n_{\text {Pol:NT }}} \sum_{i=1}^{n_{\text {Pub:NT }}} \frac{1}{g_{2}\left(r_{P_{\text {Pol:NT }}, P u b: N T_{i}}\right)}\left\{\left(h_{1}\left(\psi_{\text {Pol:NT }}\right) \widehat{\text { Pol :NT }}\right)\right. \\
& \left.\times\left[\left(h_{4 a}\left(\psi_{\text {Pub:NTa }}\right) \widehat{P u b: N T_{a}}\right)+\left(h_{4 b}\left(\psi_{\text {Pub:NTb }}\right) \widehat{P u b: N T_{b}}\right)\right]\right\} \\
& +\sum_{j=1}^{n_{\text {Pol:NQQ }}} \sum_{i=1}^{n_{P \text { Pub:RT }}} \frac{1}{g_{3}\left(r_{P_{\text {ol: }: N Q_{j}, P u b: R T_{i}}}\right)}\left\{\left(h_{2}\left(\psi_{\text {Pol:NQ }}\right) \widehat{P o l: N Q}\right)\right. \\
& \left.\times\left[\left(h_{3 a}\left(\psi_{\text {Pub:RTa }}\right) \widehat{\text { Pub:RT }}\right)+\left(h_{3 b}\left(\psi_{\text {Pub:RTb }}\right) \widehat{P u b: R T_{b}}\right)\right]\right\} \\
& +\sum_{j=1}^{n_{\text {Pol:NQ }}} \sum_{i=1}^{n_{\text {Pub:NT }}} \frac{1}{g_{4}\left(r_{\text {Pol:NQ }_{j}, P u b^{\prime \prime N T_{i}}}\right)}\left\{\left(h_{2}\left(\psi_{\text {Pol:NQ }}\right) \widehat{\text { Pol }: N Q}\right)\right. \\
& \left.\times\left[\left(h_{4 a}\left(\psi_{\text {Pub:NTa }}\right) \widehat{P u b: N T_{a}}\right)+\left(h_{4 b}\left(\psi_{\text {Pub:NTb }}\right) \widehat{P u b: N T_{b}}\right)\right]\right\}+h_{5}\left(\psi_{\text {other }}\right)
\end{aligned}
$$

In Equation (22) above, the triggers have been separated out into "inherent characteristics," denoted by the a subscript, and other forms of triggers, denoted by the $b$ subscript. Both types of trigger could reasonably be considered to exist in different vector spaces since inherent characteristics and other reasons for providing a trigger could indicate different underlying decision strategies. That can give insight into whether triggers are mainly from inherent characteristics, such as race or ethnicity, or from other sources. From the GOTCHA player standpoint, response to a trigger is subconscious. A player could respond to only one form of trigger or different types of trigger. 


\section{Discussion}

Various forms of sensitivity training, awareness training, and psychological testing are certainly already in use. The question remains as to their effectiveness in the current state. It is possible, for example, for police who were oriented towards negative behaviour to go through the training and pretend to learn while in fact not changing their behaviour in practice. Indeed, even in the wake of several massive scandals, problems nevertheless continue. Perhaps there is something deeper that needs improvement. Current methods may merely be scratching the surface, no matter how well-meaning they may be, or they may simply be aimed at reducing liability or improving political public relations. The continuation of such negative interactions in the United States poses a direct threat to full achievement of Sustainable Development Goals 1, 10, and 16.

Conceptualised in the form of transactional analysis games with the framework of parallel rationality, the potential for a suboptimal outcome resulting from a police-public interaction in the form of police brutality will remain as long as there are trigger providers, regardless of the specific type of trigger. Various forms of training regarding inherent characteristic triggers may very well be unlikely to make a difference since the game is subconscious, provided that they are designed correctly. The only way for such training to remove the potential for the game in a particular officer is if it modified the officer's utility maximisation decision strategy such that it no longer included the game. Some choice modification may still take place due to training if it modifies the constraint term, including the potential for establishing artificial bridges in the Choice Wave framework. This suggests further research within the fields of psychology, criminal justice, and sociology could significantly benefit training programme development. Such research needs to incorporate the utility maximisation concepts discussed within this study and build from a framework of strategic interaction within parallel rationality.

Nevertheless, the underlying subconscious ability to play the game remains, with the potential for a suboptimal outcome remaining if those bridges are removed. Positive and negative punishments for inappropriate behaviour similarly are less effective (Oliver, 1984; Merrett \& Tang, 1994). Such punishments may be aimed at behaviour that could point to a propensity for future brutality and is not at all to suggest that appropriate action should not be taken in such cases or in cases of actual brutality. However, in the goal of removing potential for negative outcomes resulting from subconscious games, punishments merely act on the constraint portion of the decision equation and not on the underlying Choice Wave. If the punishments are removed, the constraint is altered again such that the potential for suboptimal outcome returns. There exists a potential for eventual modification of the Choice Wave, but that is difficult to predict on either an individual level or a broad scale.

Since the parallel rationality approach focuses on outcome and takes the underlying decision strategies as given, the goal of reducing police brutality can be 
reached by trying to limit the interaction between police officers who play GOTCHA and members of the public who provide the trigger, whether that trigger is in the form of an inherent characteristic or not. Policy aimed at reducing triggers would be difficult at best, particularly pertaining to inherent characteristics, the removal of which would surely be considered immoral and unethical. It is much more ethical, efficient, and practicable to focus policy on the police side. Such policy could involve psychological testing of current offices and potential recruits to help determine the potential for excessive violence and, perhaps more importantly, the potential for playing harmful transactional analysis subconscious games. Various forms of psychological testing are certainly already in use (Arrigo \& Claussen, 2003). Such testing could provide a framework upon which to build additional testing. Care must be taken, however, to avoid holding people responsible for errors that they have not yet committed and may never commit. Therefore, the use of such testing data must be treated very delicately and analysed very carefully.

Additionally, to ensure stakeholder representation, related policy could involve the establishment of a multi-stakeholder police oversight committee. Such a committee should comprise police, government officials, members of the public, members of various ethnic, racial, and religious communities (not only the minority, but also the majority to ensure complete representation), psychological experts, and law enforcement subject matter experts.

Ultimately, the situation is a delicate balance between the police, the public with whom they interact, the government, and voters (the public at large). The gaps identified in this paper that are in need of bridges are the areas that need the most focus. If incentives can be aligned, then the potential for subconscious games and other factors leading to negative police-public interaction reasonably can be reduced. This requires, again, genuine cooperation between policymakers, general public, and the police themselves. The current apparent misalignment of incentives, as modeled within the framework of parallel rationality, will continue to provide a significant challenge to overcome. The result of not doing so, however, is a continued cost to peace, true justice, and strength of institutions.

\section{Conclusion}

The situation of negative police-public interactions in the United States and elsewhere has come to the forefront as matters of concern for both government and the public. These negative interactions, which can take the form of unnecessary arrest, negative verbal exchange, violent, or even lethal force undermine institutions by eroding public faith in those institutions. Further compounding the situation in the United States is the data-driven fact that racial minorities, particularly African-American and Hispanic, of statistically significantly more likely to be the victim of police brutality and negative police interaction. This has been shown in other studies to contribute to a perpetuation of lack of trust in the police across generations in those ethnic communities. 
The application of the multipoint gravitational model within a conceptual framework of economic parallel rationality provides a robust model of behaviour relating to negative police public interactions in the United States. Subconscious games from transactional analysis may very well be taking place in negative police-public encounters. Since such encounters are inherently related to government policy, police institutional regulations, and public opinion, the application of the model is used to determine likely areas of misalignment of incentives, thereby showing where policy, procedures, and institutions can be improved. Changes in regulation and improved training and psychological evaluation may very well help improve the situation, particularly related to the possible presence of subconscious games. That is particularly important, given the tremendous power differential between the police and the public. Furthermore, the application of parallel rationality suggests that mere changes in regulations or training will not be sufficient by themselves. What is likely needed is a "bridging" institution that is independent and can hold the trust of the police, government, and the public across ethnic boundaries. Such an institution can serve to help align incentives between the various actors and stakeholders in police-public interactions, thereby potentially improving outcomes and rebuilding trust over time in institutions. This outcome is further necessary to benefit Sustainable Development Goals 1 (No Poverty), 10 (Reduced Inequalities), and 16 (Peace, Justice, and Stronger Institutions).

\section{Conflicts of Interest}

The author declares no conflicts of interest regarding the publication of this paper.

\section{References}

About the Sustainable Development Goals (n.d.). https://www.un.org/sustainabledevelopment/sustainable-development-goals/

Arrigo, B. A., \& Claussen, N. (2003). Police Corruption and Psychological Testing: A Strategy for Preemployment Screening. International Journal of Offender Therapy and Comparative Criminology, 47, 272-290. https://doi.org/10.1177/0306624X03047003003

Berman, M., \& Wax-Thibodeaux, E. (2020). As Protests Grip Cities, Violence against Police Raises Fears of Harsher Crackdown. The Washington Post.

Berne, E. (1964). Games People Play: The Psychology of Human Relationships. Grove Press.

Campos, L. P. (2014). A Transactional Analytic View of War and Peace. Transactional Analysis Journal, 44, 68-79. https://doi.org/10.1177/0362153714531722

Genovese, D. (2020, June 10). Economic Pain Worsens for Minneapolis as Businesses Exit after Riots. FoxBusiness.

https://www.foxbusiness.com/lifestyle/we-need-to-rebuild-right-with-the-community-i n-focus-minneapolis-chamber-of-commerce-says

Halushka, J. M. (2020). The Runaround: Punishment, Welfare, and Poverty Survival after Prison. Social Problems, 67, 233-250. https://doi.org/10.1093/socpro/spz018

Jaffray, J. (1992). Bayesian Updating and Belief Functions. IEEE Transactions on Systems, 
Man, and Cybernetics, 22, 1144-1152. https://doi.org/10.1109/21.179852

Johnson, R. (2007). Health Information and Consumer Types in the Domestic Cracker Market. Doctoral Dissertation, University of Kentucky.

Johnson, R. (2012). The Choice Wave: An Alternative Description of Consumer Behaviour. Research in Business and Economics Journal, 5, 1-16.

Johnson, R. (2013). A Subconscious Game with Economic Consequences: An Economic Analysis based on Psychological Transactional Analysis and a Classic Game of Eric Berne. Review of Religion, Economics, and Culture, 2, 57-71.

Johnson, R. (2015). Decline in Church Giving in the United States during the Recession: A Spatial Application of Choice Waves. Journal of Behavioral Studies in Business, 8, 1-15.

Johnson, R. (2016). A Probabilistic Demand Application in the American Cracker Market. International Journal of Food and Agricultural Economics, 4, 49-61.

Johnson, R. (2017). Choice Waves and Strategic Interaction. Journal of Technology Research, 7, 1-12.

Johnson, R. (2017a). The Inclusion of Geo-Cultural, Historical, and Legal Considerations in the Analysis of Anglican and Roman Ecclesiastical Division. Interdisciplinary Journal of Research on Religion, 13, 1-22.

Johnson, R. (2017b). An Economic Multipoint Gravitational Model Expression of a Transactional Analysis Game: An Application to Recreational Private Land Use Decisions. Journal of Applied Business Research, 33, 791-800.

https://doi.org/10.19030/jabr.v33i4.10000

Johnson, R., \& Walker II, E. (2018). A Probabilistic Shortage of Private Land Opened to Hunters in Northwest Minnesota. Modern Economy, 9, 213-240. https://doi.org/10.4236/me.2018.91014

Kahneman, D., \& Tversky, A. (1979). Prospect Theory: An Analysis of Decision under Risk. Econometrica, 47, 263-292. https://doi.org/10.2307/1914185

Koran, M. (2020, June 12). 'We're Suffering the Same Abuses': Latinos Hear Their Stories Echoed in Police Brutality Protests. The Guardian.

https://www.theguardian.com/world/2020/jun/12/latinos-police-brutality-protests-geo rge-floyd

Ledgerwood, A., Chaiken, S., Gruenfeld, D. H., \& Judd, C. M. (2006). Changing Minds: Persuasion in Negotiation and Conflict Resolution. In M. Deutsch, P. T. Coleman, \& E. C. Marcus (Eds.), The Handbook of Conflict Resolution: Theory and Practice (pp. 455-485). Wiley Publishing.

Mannix, E. A., \& Neale, M. A. (1993). Power Imbalance and the Pattern of Exchange in Dyadic Negotiation. Group Decision and Negotiation, 2, 119-133.

https://doi.org/10.1007/BF01884767

Merelli, A. (2020, June 6). To Stop Police Brutality, Make It Financially Unsustainable. QZ.

https://qz.com/1864979/to-stop-police-brutality-make-it-financially-unsustainable/

Merrett, F., \& Tang, W. M. (1994). The Attitudes of British Primary School Pupils to Praise, Rewards, Punishments and Reprimands. British Journal of Educational Psychology, 64, 91-103. https://doi.org/10.1111/j.2044-8279.1994.tb01087.x

Mock, B. (2020, June 4). How Cities Offload the Cost of Police Brutality. Bloomberg.

Oliver, P. (1984). Rewards and Punishments as Selective Incentives: An Apex Game. Journal of Conflict Resolution, 28, 123-148.

https://doi.org/10.1177/0022002784028001007 
Outland, R. (2021). Why Black and Brown Youth Fear and Distrust Police: An Exploration of Youth Killed by Police in the US (2016/2017), Implications for Counselors and Service Providers. Open Journal of Social Sciences, 9, 222-240.

https://doi.org/10.4236/jss.2021.94017

Peoples, L. (2020). What the Data Say about Police Brutality and Racial Bias-And Which Reforms Might Work. Nature. https://doi.org/10.1038/d41586-020-01846-Z https://www.nature.com/articles/d41586-020-01846-Z

Rabin, M. (1998). Psychology and Economics. Journal of Economic Literature, 36, 11-46.

Rodenberg, H. (2020). Understanding Police Violence as a Mutual Problem. American Journal of Public Health, 110, 456-457. https://doi.org/10.2105/AJPH.2020.305585

Russell, T., \& Thaler, R. (1985). The Relevance of Quasi Rationality in Competitive Markets. American Economic Review, 75, 1071-1072.

Trinkner, R., Kerrison, E. M., \& Goff, P. A. (2019). The Force of Fear: Police Stereotype Threat, Self-Legitimacy, and Support for Excessive Force. Law and Human Behavior, 43, 421-435. https://doi.org/10.1037/lhb0000339

Wei, Q., \& Luo, X. (2012). The Impact of Power Differential and Social Motivation on Negotiation Behavior and Outcome. Public Personnel Management, 41, 47-58. https://doi.org/10.1177/009102601204100505 